Vol. 6, No. 1 Januari - Juni 2017

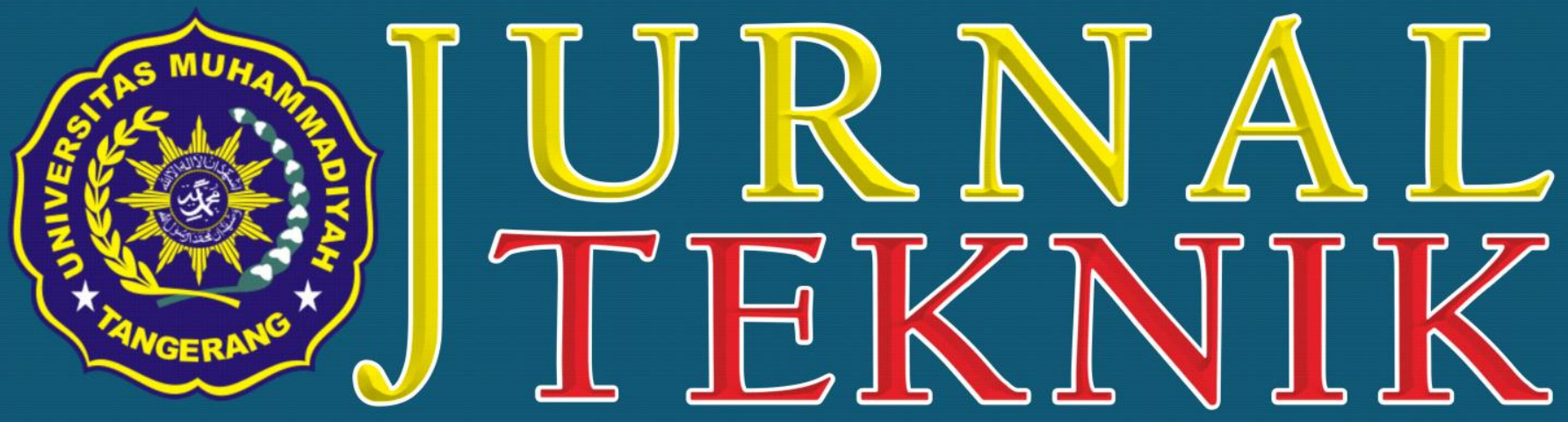

Alamat Redaksi: Jl. Perintis Kemerdekaan I No. 33, Cikokol Tangerang - TIp. (021) 51374916

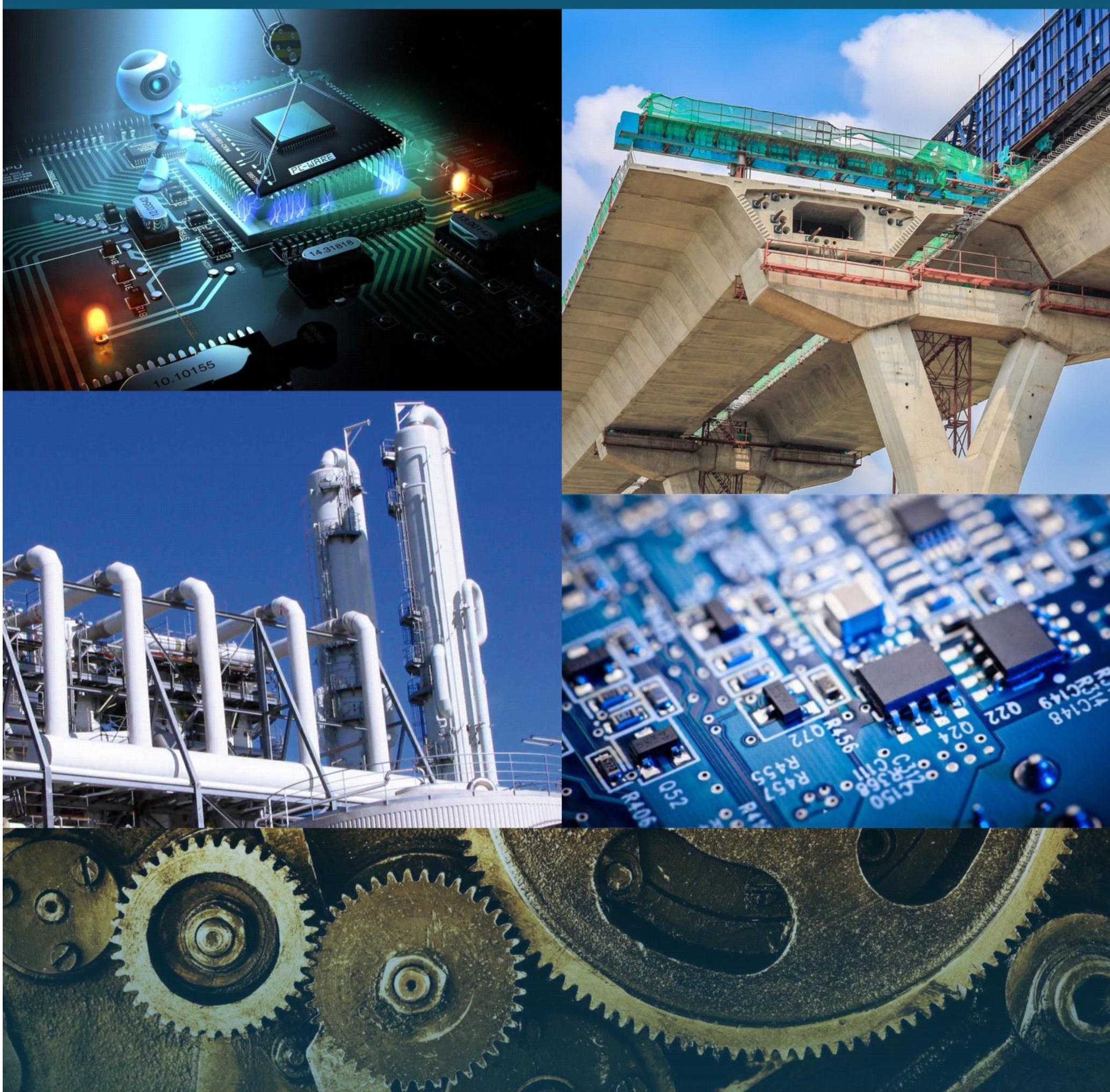




\section{J U R N A L TEKN I K}

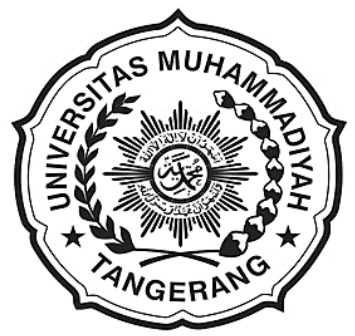

\section{UNIVERSITAS MUHAMMADIYAH TANGERANG}

Pelindung:

Dr. H. Achmad Badawi, S.Pd., SE., MM. (Rektor Universitas Muhammadiyah Tangerang)

Penanggung Jawab:

Ir. Saiful Haq, ST., M.Si.

(Dekan Fakultas Teknik)

Pembina Redaksi:

Rohmat Taufik, ST., M.Kom.

Drs. H. Syamsul Bahri, MSi.

Pimpinan Redaksi:

Ir. Sumardi Sadi, S.Pd., ST., MT.

Redaktur Pelaksana:

Yafid Efendi, ST, MT.

Editor Jurnal Teknik UMT:

Ir. Sumardi Sadi, S.Pd., ST., MT.

Dewan Redaksi:

Ir. Ali Rosyidin, ST., MM., MT.

Tri Widodo, ST.,MT.

Tina Herawati, ST., MT

Almufid, ST., MT.

Siti Abadiah, ST., MT.

M. Jonni, SKom., MKom.

Syepry Maulana Husain, S.Kom., M.Kom.

Ir. H. Bayu Purnomo, ST., MT

Kasubag:

Ferry Hermawan, MM.

Keuangan:

Elya Kumalasari, S.Ikom.

Setting \& Lay Out:

Muhlis, S.E

Saiful Alam, SE.

Mitra Bestari:

Prof. Dr. Aris Gumilar

Ir. Doddy Hermiyono, DEA

Dr. Ir. Budiyanto, MT.

Dr. Alimuddin, ST., MM., MT

J U R N A L T E K N I K

Diterbitkan Oleh:

Fakultas Teknik Universitas Muhammadiyah Tangerang

Alamat Redaksi:

Jl. Perintis Kemerdekaan I No. 33, Cikokol Tangerang Tlp. (021) 51374916

\begin{tabular}{|c|c|c|c|c|c|}
\hline \multirow{2}{*}{$\begin{array}{c}\text { Jurnal } \\
\text { Teknik }\end{array}$} & 6 & 1 & $1-97$ & $\begin{array}{c}\text { Jan'-Juni } \\
2017\end{array}$ & ISSN \\
\cline { 2 - 6 } & $2302-8734$ \\
\hline
\end{tabular}

\section{DAFTAR ISI}

1. PROSES PEMBUATAN ALAT PEMBUKA KALENG CAT DENGAN METODE CETAK PASIR (SAND CASTING) - 1-11 Ali Rosyidin

2. ANALISA DAN PERANCANGAN SISTEM KENDALI PLC XBC MINI BAS - 12-18 Alim Hardiansyah \& Bambang Suardi Waluyo

3. PENGATUR KESTABILAN SUHU PADA EGG INCUBATOR BERBASIS ARDUINO - 19-22

Abel Putra Hidayah \& Sumardi Sadi

4. METODE PEMBUATAN PONDASI BORE PILE DENGAN KINGPOST DAN METODE PONDASI DINDING PENAHAN TANAH DIAFRAGMA WALL - 23-29

Almufid

5. RANCANG BANGUN SIMULASI PENGENDALI LAMPU LALU LINTAS PADA PERSIMPANGAN DENGAN LIMA JALUR - 30-39

Rahma Farah Ningrum, Puji Catur Siswipraptini, \& Rosida N. Aziza

6. PERANCANGAN PROGRAM APLIKASI PENGENALAN WAJAH DENGAN MENERAPKAN METODE PRINCIPAL COMPONENT ANALYSIS DAN JARINGAN SYARAF TIRUAN - 40-49

M. Lutfi Aksani

7. KAJIAN PENERAPAN SI / TI DALAM MENINGKATKAN KUALITAS PEMBELAJARAN PADA TRAINING CENTER DENGAN MENGGUNAKAN METODOLOGI DeLone And McLean: STUDI KASUS PADA BINUS CENTER JAKARTA - 50-62 Nyoman Ayu Gita Gayatri \& GG Faniru Pakuning Desak

8. RANCANG BANGUN APLIKASI PEMBELAJARAN MATEMATIKA SD KELAS 6 BERBASIS ANDROID PADA SDN CIMONE 1 TANGERANG - 63-69

Winda Anggraeni \& Sri Mulyati

9. RANCANG BANGUN MESIN PERAJANG SINGKONG INDUSTRI RUMAHAN BERDAYA RENDAH - 70-76

Yafid Effendi \& Agus Danang Setiawan

10. RANCANG BANGUN TONGKAT ULTRASONIK UNTUK PENYANDANG TUNA NETRA BERBASIS ARDUINO UNO - 77-82

Bayu Purnomo \& Basuki Isnanto

11. ENTERPRISE RISK MANAGEMENT PADA CLOUD COMPUTING - 83-87

Samudera Dipa Legawa

12. ANALISIS NETWORK PLANNING DENGAN CRITICAL PATH METHOD (CPM) PADA PROYEK UNINTERATUBLE POWER SUPPLY (UPS) 80KVA PADA PT. HARMONI MITRA SUKSES (STUDI KASUS: RSAB HARAPAN KITA, JAKARTA) - 88-97

Hermanto, Novy Fauziah, \& Elfitria Wiratmani 


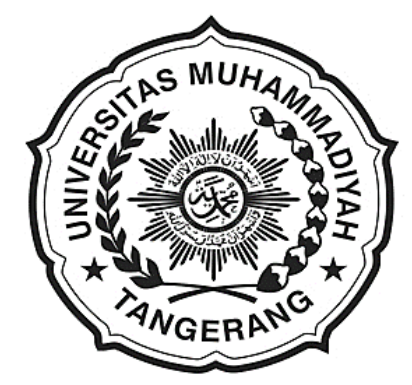

\section{Sambutan Dekan \\ Fakultas Teknik \\ Universitas Muhammadiyah Tangerang}

Puji Syukur kehadirat Allah Swt. karena berkat karunia dan ijin-Nyalah Tim penyusun Jurnal Teknik Fakultas Teknik Universitas Muhammadiyah Tangerang dapat menyelesaikan tugasnya tepat sesuai dengan waktu ditetapkan.

Saya menyambut baik diterbitkannya Jurnal Teknik Vol. 6 No. 1, Januari-Juni 2017, terbitnya jurnal ini, merupakan respon atas terbitnya Peraturan Menteri Pendidikan Nasional No. 17 Tahun 2010 tentang Pencegahan dan Penanggulangan Plagiat di Perguruan Tinggi; Surat Dirjen Dikti Nomor 2050/E/T/2011 tentang kebijakan unggah karya ilmiah dan jurnal; Surat Edaran Dirjen Dikti Nomor 152/E/T/2012 tertanggal 27 Januari 2012 perihal publikasi karya ilmiah yang antara lain menyebutkan untuk lulusan program sarjana terhitung mulai kelulusan setelah 2012 harus menghasilkan makalah yang terbit pada jurnal ilmiah.

Terbitnya Jurnal ini juga diharapkan dapat mendukung komitmen dalam menunjang peningkatan kemampuan para dosen dan mahasiswa dalam menyusun karya ilmiah yang dilandasi oleh kejujuran dan etika akademik. Perhatian sangat tinggi yang telah diberikan rektor Universitas Muhammadiyah Tangerang khususnya mengenai plagiarism dan cara menghindarinya, diharapkan mampu memacu semangat dan motivasi para pengelola jurnal, para dosen dan mahasiswa dalam menyusun karya ilmiah yang semakin berkualitas.

Saya mengucapkan banyak terimakasih kepada para penulis, para pembahas yang memungkinkan jurnal ini dapat diterbitkan, dengan harapan dapat dimanfaatkan seoptimal mungkin dalam peningkatan kualitas karya ilmiah.

Dekan Fakultas Teknik

Universitas Muhammadiyah Tangerang,

\section{Ir. Saiful Haq, M.Si.}




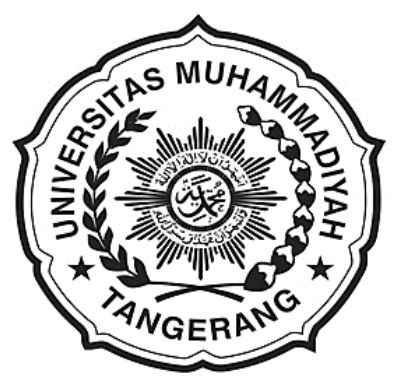

\section{Pengantar Redaksi}

Jurnal Teknik

Universitas Muhammadiyah Tangerang

Puji dan Syukur Alhamdulillah kami panjatkan kehadapan Allah Swt. atas karunia dan lindungan-Nya sehingga Jurnal Teknik Vol. 6 No. 1 edisi Januari-Juni 2017 dapat diterbitkan.

Menghasilkan karya ilmiah merupakan sebuah tuntutan perguruan tinggi di seluruh dunia. Tri Dharma Perguruan Tinggi yaitu darma pendidikan, darma penelitian, dan darma pengabdian kepada masyarakat mendorong lahirnya dinamika intelektual diantaranya menghasilkan karyakarya ilmiah. Penerbitan Jurnal Teknik ini dimaksudkan sebagai media dokumentasi dan informasi ilmiah yang sekiranya dapat membantu para dosen, staf dan mahasiswa dalam menginformasikan atau mempublikasikan hasil penelitian, opini, tulisan dan kajian ilmiah lainnya kepada berbagai komunitas ilmiah.

Buku Jurnal yang sedang Anda pegang ini menerbitkan 12 artikel yang mencakup bidang teknik sebagaimana yang tertulis dalam daftar isi dan terdokumentasi nama dan judul-judul artikel dengan jumlah halaman 1-97 halaman.

Jurnal Teknik ini tentu masih banyak kekurangan dan masih jauh dari harapan, namun demikian tim redaksi berusaha untuk ke depannya menjadi lebih baik dengan dukungan kontribusi dari semua pihak. Harapan Jurnal Teknik akan berkembang menjadi media komunikasi intelektual yang berkualitas, aktual dan faktual sesuai dengan dinamika di lingkungan Universitas Muhammadiyah Tangerang.

Tak lupa pada kesempatan ini kami mengundang pembaca untuk mengirimkan naskah ringkasan penelitiannya ke redaksi kami. Kami sangat berterimakasih kepada semua pihak yang telah membantu penerbitan Jurnal Teknik ini semoga buku yang sedang Anda baca ini dapat bermanfaat.

Pimpinan Redaksi Jurnal Teknik

Universitas Muhammadiyah Tangerang,

Ir. Sumardi Sadi, S.Pd., ST., MT. 


\title{
PENGATUR KESTABILAN SUHU PADA EGG INCUBATOR BERBASIS ARDUINO
}

\author{
Abel Putra Hidayah ${ }^{1)}$, Sumardi Sadi ${ }^{1)}$ \\ 1,2) Program Studi Teknik Elektro \\ Universitas Muhammadiyah Tangerang \\ Jl. Perintis Kemerdekaan I/33, Cikokol - Tangerang-Banten \\ E-mail:mardiesadi99@gmail.com
}

\begin{abstract}
ABSTRAK
Secara umum mesin penetas telur atau egg incubator digunakan untuk meningkatkan produkstifitas penetasan telur unggas seperti Ayam dan Bebek. Penggunaan alat ini sepertihalnya pada proses pengeraman yang dilakukan indukan, terdapat beberapa variable yang dikontrol untuk mengembangkan embrio dalam telur salah satu variabelnya adalah suhu. Untuk meningkatkan daya tetas mesin telur diperlukan suatu kesetabilan dan homogenitas suhu pada ruangan penetasan. Untuk itulah digunakan system kontrol PID agar kestabilan suhu dapat terjaga. Dengan menggunakan Arduino sebagai pengontrol utama, hasil pembacaan sensor akan diproses sesuai dengan Algoritma PID yang telah ditanamkan dalam minimum sistem. Lalu akan disesuaikan dengan Set Point yang telah ditetapkan. Output dari alat berupa sinyal digital yang akan mengontrol elemen pemanas berupa lampu pijar. Saat selisih suhu dengan Set Point melebihi $5^{\circ} \mathrm{C}$ maka Elemen pemanas akan digunakan. Dan dalam deviasi $5^{\circ} \mathrm{C}$ lampu pijar digunakan untuk memanaskan ruang tetas.
\end{abstract}

Kata Kunci: PID, Arduino, Mesin Tetas Telur.

\section{PENDAHULUAN}

Mesin penetas telur atau lebih dikenal dengan egg incubator, merupakan suatu alat yang digunakan untuk mengatur keadaan suatu ruang sesuai dengan kondisi dalam proses pengeraman yang dilakukan oleh indukan unggas seperti ayam, angsa, itik dan burung puyuh. Alat ini digunakan untuk meningkatkan produktifitas unggas dalam berkembang biak. Saat indukan unggas mengerami telur maka indukan tidak dapat bertelur. Sehingga dengan adanya alat ini indukan dapat terus bertelur dan telur dapat menetas.

Namun kondisi yang ada, tingkat mortalitas embrio dalam proses ini cukup tinggi. Sehingga dapat menyebabkan kerugian bagi peternak. Terdapat beberapa faktor yang mempengaruhi penetasan telur. Salah satu diantaranya adalah suhu ruang penetasan. Karena sebagian besar pengaturan suhu dilakukan dengan metode On Off, sehingga terdapat deviasi suhu yang rentan menyebabkan mortalitas embrio.

Secara umum persentase keberhasilan penetasan telur dengan menggunakan mesin penetas telur dipengaruhi oleh dua faktor utama yakni faktor internal alat dan eksternal alat. Yang dimaksud faktor eksternal adalah faktor-faktor yang mempengaruhi fertilitas diluar dari daya kerja mesin seperti pembuahan telur oleh unggas pejantan, berat telur, bentuk telur, keutuhan kulit telur, kualitas kulit telur, warna kulit telur, kebersihan kulit telur dan temperatur penyimpanan telur.

Sementara itu, yang dimaksud faktor internal alat adalah variabel-variabel dalam alat penetas yang diatur sedemikian rupa untuk mencapai kondisi yang paling ideal sesuai dengan kebutuhan telur. Seperti suhu, kelembaban, ventilasi dan pembalikan posisi telur. Faktor internal alat ini sangat krusial untuk meminimalkan tingkat mortalitas embrio. Misalnya adalah suhu pada ruang tetas. Secara konvensional, pengaturan suhu dilakukan dengan metode digital dengan bantuan thermostat yang digunakan untuk menyalakan dan memadamkan lampu pijar untuk meradiasiakan panas di ruang tetas. Dan penem- 
patan thermostat di dalam ruang tetas untuk merepresentasikan suhu ruang tetas.

Thermostat yang umumnya digunakan memiliki skala pembacaan terkecil hingga $1^{\circ} \mathrm{C}$ dengan toleransi $\pm 0,5^{\circ} \mathrm{C}$. Tentu hal ini menjadi suatu celah peningkatan tingkat mortalitas embrio. Karena menurut penelitian The Effect Of Temperature On Hatchability And Egg Hatching Yield Duck dalam Jurnal Ilmiah Peternakan 2013 disetiap $2^{\circ} \mathrm{C}$ selisih suhu penetasan dengan suhu optimal penetasan, tingkat mortalitas akan meningkat $44,61 \%$. Selain itu pemosisian satu thermostat untuk mewakili seluruh volume ruang tetas tidak dapat merepresentasikan nilai pembacaan suhu secara akurat bilamana suhu dalam ruang tetas tidaklah homogen. Sehingga hal ini menjadi faktor baru yakni selain kestabilan diperlukan juga kehomogenan suhu dalam ruang tetas.

Oleh karena itu, Penulis merancang suatu pengaturan kestabilan suhu egg incubator dengan metode PID berbasis Arduino untuk meningkatkan persentase daya tetas telur.

Tujuan penelitian ini memiliki tendensi sebagai berikut:

1. Dapat mengoptimalkan dan meningkatkan produktifitas penetasan telur;

2. yang umumnya digunakan peternak;

3. Mempermudah peternak dalam melakukan kegiatan penetasan telur;

4. Mendesain prototype alat yang fleksibel dan dengan praktis diterapkan; dan

5. dalam kehidupan.

\section{METODE PENELITIAN}

Dalam melakukan penelitian ini dipergunakan metode rancang bangun serta pengumpulan data yang didapat berasal dari analisis hasil yang diberikan oleh alat. Sebelum merealisasikan alat terlebih dahulu penulis menyusun perancangan sistem secara utuh agar tujuan dari penelitian dapat tercapai. Pada bagian ini, Penulis membagi menjadi beberapa perancangan yang nantinya akan diimplementasikan langkah demi langkah. Langkah pertama penulis merancang perangkat keras yang akan digunakan dalam pengontrolan suhu egg incubator ini. Langkah kedua, penulis merancang perangkat lunak yang dibutuhkan untuk menunjang pengontrolan yang akan dilakukan. Langkah ketiga, penulis merancang pengimplementasian pe- rangkat mekanis yang juga merupakan bagian penting dalam penelitian ini.

\section{Perancangan Perangkat Pengontrol}

Sesuai dengan permasalahan yang diangkat dalam penelitian ini, perangkat keras (perangkat pengontrol) dirancang hanya untuk mengatur kestabilan suhu dalam egg incubator dengan menggunakan aksi kontrol PID. Sehingga, perangkat yang akan digunakan nantinya hanya memiliki fungsi spesifik. Walau demikian, perangkat pengontrol yang dimaksud juga dapat kembali dikembangkan diluar penelitian ini guna mendapat fungsi yang aplikatif. Mengingat diperlukan beberapa pengontrolan variabel untuk dapat menggunakan egg incubator dalam menetaskan telur.

Perangkat kontrol ini terdiri dari beberapa bagian, yaitu catu daya yang akan digunakan Arduino dan perangkat pendukung lainnya, Arduino nano sebagai minimum sistem pengontrolan, sensor sebagai masukan Arduino untuk membaca suhu pada egg incubator, LCD yang akan digunakan sebagai perangkat grafis untuk menampilkan data yang diproses Arduino, Relay sebagai pengantarmuka dari minimum system terhadap lampu pijar yang akan digunakan untuk memanaskan egg incubator dan push button sebagai masukan untuk melakukan penggeseran tampilan LCD. Secara keseluruhan, perangkat pengontrol dijelaskan pada blok diagram 1.

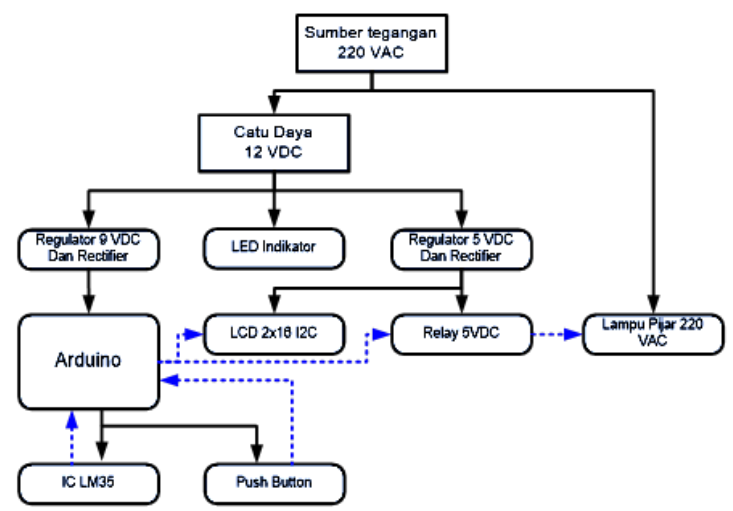

Gambar 1 Blok diagram pengontrolan 


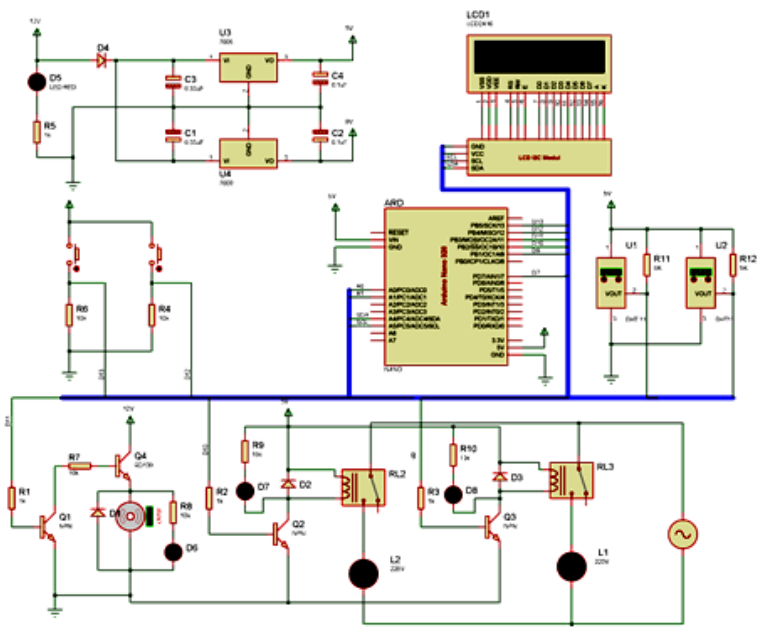

Gambar 2 Perancangan Sistematis

\section{HASIL DAN PEMBAHASAN}

Distribusi hasil pembacaan suhu antara thermo hygrometer dan pembacaan suhu Incubator
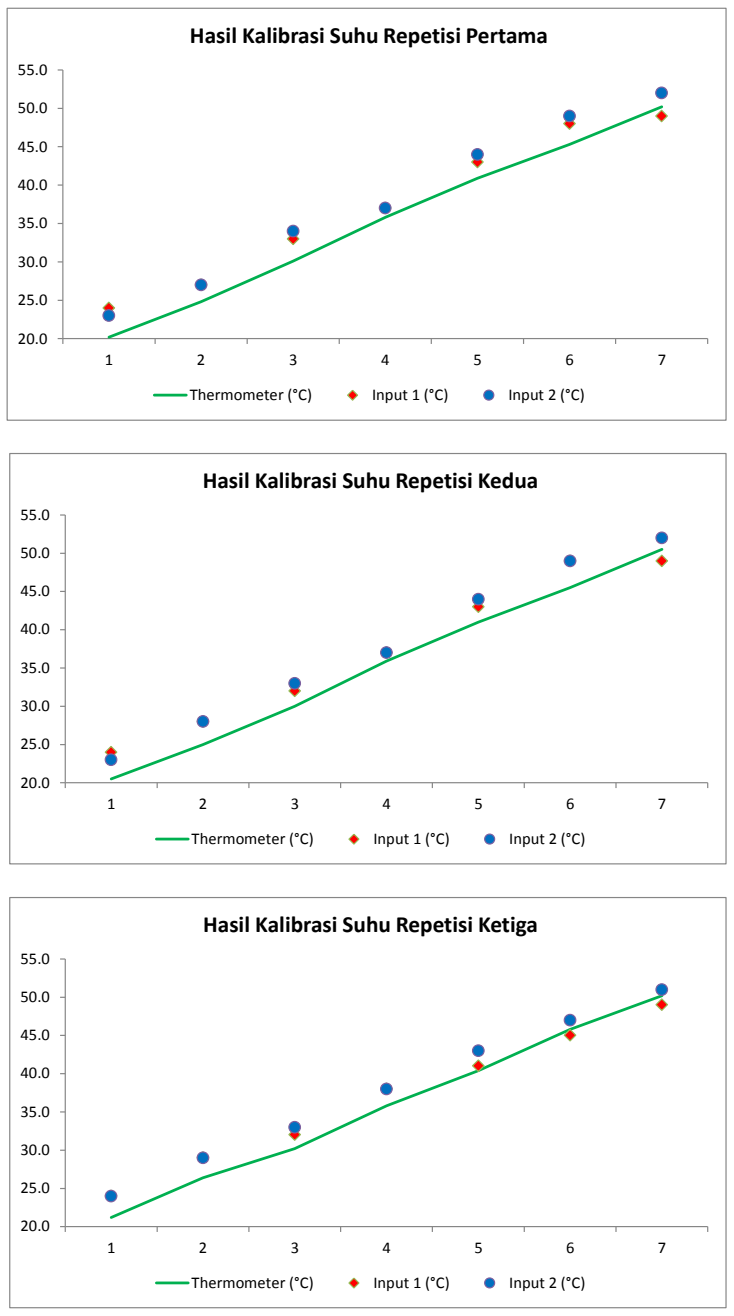

Gambar 3 Grafik pengujian pembacaan termometer dan incubator

\section{KESIMPULAN}

Berdasarkan repetisi pertama persamaan yang didapat dari pembacaan suhu thermo hygrometer, terdapat perbedaan suhu antara sensor satu dengan rata-rata $1,96^{\circ} \mathrm{C}$ sedangkan untuk sensor dua memiliki ratarata perbedaan $2,67^{\circ} \mathrm{C}$. Perbedaan suhu ini selanjutnya akan disebut sebagai nilai koreksi yang didapat dari rata-rata selisih pembacaan suhu dari titik uji terndah yakni $20^{\circ} \mathrm{C}$ hingga suhu tertinggi $55^{\circ} \mathrm{C}$.

\section{DAFTAR PUSTAKA}

Gabel, Robert R. dan Mahan, Thomas A, 2006 Incubation and Hatching, Journal of USGS, Vol 2 No1, Desember 2006, pp. 59-70.

Ningtyas, Maulidia, 2013. Pengaruh Temperatur Tehadap Daya Tetas dan Hasil Tetas Telur Itik, Jurnal Ilmiah Peternakan, Vol.1 No. 11, April 2013, pp.347-352.

Ichsan Dwi, Nugroho, 2012. Alat Pengatur Lampu dan Pembalik Telur Otomatis pada Bok Penetasan Telur Berbasis Mikrokontroler Atmega 16 Dilengkapi Uninterruptible Power Supply, Skripsi, Jurusan Teknik Elektronika FT UNY, Yogyakarta.

Bachari, Irawati, Sembiring, Iskandar, dan Tarigan, Suranta, 2006, Pengaruh Frekuensi Pemutaran Telur Terhadap Daya Tetas dan Bobot Badan DOC Ayam Kampung, Jurnal Agribisnis Peternakan, Vol. 2, No. 3, Desember 2006, pp. 101-105.

Tehrani,Arab, Kambiz dan Mpanda, Augutin. (2012). Introduction to PID Controllers, Indiana: InTech.

Dunn, D.J., 2011, PID Control Action Response, Journal of Electrical Engineering, Vol 4. No12, Juni 2011, pp. 235-246. 
Ali, Muhammad, 2004, Pembelajaran Perancangan Sistem Kontrol PID dengan Software Matlab, Jurnal Edukasi@Elketro Vol. 1, No.1, Oktober 2004, pp. 1-8.

Arduino - Product - Sabtu, 2 Juli 2016 https://www.arduino.cc/en/Main/Ard uinoBoardUno.

Agidi, Gbabo, Liberty, J.T., Gunre, O.N., dan Owa, G.J., 2013, Design, Construction and Performance Evaluation of An Electric Powered Egg Incubator, International Journal of Research in Engineering and Technology, Vol. 3 No.3, Maret 2014, pp. 521-526.
Brett Beauregard - Improving PID $\begin{array}{llll}\text { Minggu } & 3 & \text { Juli } & 2016\end{array}$ http://brettbeauregard.com/blog/2011 /04/improving-the-beginners-pidintroduction/

Processing - Overview - Minggu 3 Juli 3016

https://processing.org/overview/ 